\title{
Application of Monohydroxyphthalocyanines for Selective Preparation of Homo- and Heteroligand Macrocyclic Compounds
}

\author{
Alexander Yu. Tolbina ${ }^{\mathrm{a} b \mathrm{~b}}$ and Larisa G. Tomilova ${ }^{\mathrm{a}, \mathrm{b}}$ \\ ${ }^{a}$ M.V. Lomonosov Moscow State University, Moscow, 119991, Russia \\ ${ }^{\mathrm{b}}$ Institute of Physiologically Active Compounds, Russian Academy of Sciences, Chernogolovka, Moscow Region, \\ 142432, Russia \\ @Corresponding author E-mail: tom@org.chem.msu.ru
}

\begin{abstract}
The direct synthesis of functionally substituted monohydroxyphthalocyanines has been developed with application of
\end{abstract} these compounds as building-blocks for synthesizing homo- and heteroligand bisphthalocyanine complexes.

Keywords: Phthalocyanine, subphthalocyanine, selective synthesis, nucleophilic substitution, heteroligand complex.

\section{Introduction}

Unsymmetrically substituted monophthalocyanines represent considerable interest not only from theoretical, but also from the practical point of view. Functional substitution of various nature in such macrocyclic compounds allows to design new supramolecular structures possessing unique physical and chemical properties. ${ }^{[2,3]}$ For this reason development of the direct synthetic methods for these compounds is one of priority field in phthalocyanine chemistry.

\section{Experimental}

${ }^{1} \mathrm{H},{ }^{11} \mathrm{~B}$ NMR spectra were registered on Brucker AM-300 (300.13 MHz), using $\mathrm{Py}-\mathrm{d}_{5}$ and $\mathrm{CDCl}_{3}$ as the solvents. Mass spectra were obtained on Autoflex II (MALDI-TOF) equipment. IR-spectra were recorded on Nicolet Nexus IR-Furje ( $\mathrm{KBr}$ pills). UV-vis spectra were recorded on ThermoSpectronic Helios- $\alpha$ spectrophotometer in quartz cell $\left(\mathrm{CHCl}_{3}, \mathrm{THF}\right)$. Chromatographyc separation was carried out on Merck Silicagel $60(40 \times 63 \mu \mathrm{m})$ and Biorad BioBeads (SX-1).

$\mathrm{Zn}(\mathrm{OAc})_{2} \cdot 2 \mathrm{H}_{2} \mathrm{O}$ salt was kept under $100^{\circ} \mathrm{C}$ for $4 \mathrm{~h}$ before synthesis. $\mathrm{CH}_{3} \mathrm{OLi}$ was freshely prepared and used immediately.

Compounds 1 1 $^{[1]} \mathbf{2}^{[4]}$ and $\mathbf{6}^{[7]}$ were obtained according to described procedures.

2-Hydroxysubstituted phthalocyanine, 3. $\mathrm{CH}_{3} \mathrm{OLi}(0.32 \mathrm{~g}$, $8.33 \mathrm{mmol})$ was added to the solution of compounds $1(0.15 \mathrm{~g}$, $0.64 \mathrm{mmol})$ and $2(1.18 \mathrm{~g}, 6.41 \mathrm{mmol})$ in $n$-hexanol $(20 \mathrm{ml})$. The mixture was refluxed for $2 \mathrm{~h}$, and then the solvent was evaporated with following treatment of crude product with conc. $\mathrm{H}_{2} \mathrm{SO}_{4}$. The reaction mixture was kept for $5 \mathrm{~min}$ and poured onto ice. The phthalocyanine products precipitated were filtered off, repeatedly washed with water to neutral $\mathrm{pH}$, and chromatographed on silica gel $\left(\mathrm{CHCl}_{3}\right)$ to give compound 3. Yield $0.24 \mathrm{~g}(50 \%)$. IR (KBr) $v$ $\mathrm{cm}^{-1}:$ 3200-3300 (OH). MS (m/e) $760[\mathrm{MH}]^{+} .{ }^{1} \mathrm{H}$ NMR $\left(\mathrm{Py}_{-} \mathrm{d}_{5}\right) \delta_{\mathrm{H}}$ ppm: 1.21-1.38 (group s, 27H, $\left.\mathrm{C}\left(\mathrm{CH}_{3}\right)_{3}\right), 8.75-9.12$ (m, 12H, Pc). UV-vis $\left(\mathrm{CHCl}_{3}\right) \lambda_{\max }$ nm: 350, 611, 679.

Bis(bromomethyl)benzene, 4 . To the solution of o-xylene (1 $\mathrm{ml}, 8.29 \mathrm{mmol})$ in $\mathrm{CCl}_{4}(5 \mathrm{ml})$ bromine $(0.9 \mathrm{ml}, 18.24 \mathrm{mmol})$ was added dropwise at lighting ( $300 \mathrm{~W}$ halogen lamp) and refluxing for $30 \mathrm{~min}$. After reaction was finished the mixture was cooled and concentrated followed by filtration of target compound to give $2 \mathrm{~g}$ of 4 (82\%). CAS 91-13-4, PubChem Substance ID: 24893875

Homonuclear clamshell-type complex, 5. NaH (2 mg, 0.080 mmol) was added to a solution of compound 3a ( $85 \mathrm{mg}, 0.111$ $\mathrm{mmol}$ ) in DMF (2 $\mathrm{ml})$. Once the reaction was completed, reagent $4^{[4]}(17 \mathrm{mg}, 0.056 \mathrm{mmol})$ was added to the reaction mixture with vigorous stirring, and the mixture was kept for 15-20 min at 25$30^{\circ} \mathrm{C}$ with chromatographic monitoring of the reaction. The reaction mixture was treated with water; the precipitated product was filtered off, washed with water $(3 \times 10 \mathrm{ml})$, then with methanol $(2 \times 10 \mathrm{ml})$, and purified by chromatography on silica gel (Merck, $\left.40 \times 63 \mu \mathrm{m}, \mathrm{CHCl}_{3}-\mathrm{THF}=20: 1\right)$ to give $86 \mathrm{mg}(95 \%)$ of complex $\mathbf{5}$. MS $(m / e) 1626[\mathrm{MH}]^{+}, 761\left[\mathrm{M}-\mathrm{C}_{52} \mathrm{H}_{49} \mathrm{~N}_{8} \mathrm{OZn}\right]^{+} .{ }^{1} \mathrm{H}$ NMR $\left(\mathrm{Py}-\mathrm{d}_{5}\right) \delta_{\mathrm{H}}$ ppm: 1.2-1.4 (group s, 54H, C( $\left.\left.\mathrm{CH}_{3}\right)_{3}\right), 5.5$ (s, 4H, OC $\left.\underline{H}_{2}\right), 8.70-9.10$ (m, 28H, Ar). UV-vis $\left(\mathrm{CHCl}_{3}\right) \lambda_{\text {max }}$ nm: 336, 637, 678.

Heteronuclear clamshell-type complex, 7. Compound 3 (15 $\mathrm{mg}, 0.02 \mathrm{mmol}$ ) was added to a solution of compound $\mathbf{6}^{[5]}(18 \mathrm{mg}$, $0.03 \mathrm{mmol})$ in toluene $(5 \mathrm{ml})$. The mixture was refluxed for $25 \mathrm{~h}$ and then concentrated in vacuo. The target product 7 was isolated by chromatography on BioBeads SX1. The yield of compound 7 was $24 \mathrm{mg}(90 \%)$. MS (m/e): $1340[\mathrm{M}-\mathrm{H}]^{+}, 579\left[\mathrm{M}-\mathrm{C}_{44} \mathrm{H}_{30} \mathrm{~N}_{8} \mathrm{OZn}\right]^{+}$. ${ }^{1} \mathrm{H}$ NMR (Py-d $\left.\mathrm{d}_{5}\right) \delta_{\mathrm{H}}$ ppm: 1.2-1.4 (group s, 54H), 8.70-9.10 $(\mathrm{m}, 21 \mathrm{H}) .{ }^{11} \mathrm{~B}$ NMR $\left(\mathrm{CDCl}_{3}\right) \delta_{\mathrm{B}} \mathrm{ppm}:-15.20$ (s, B). UV-vis (THF) $\lambda_{\max }$ nm: $348,573,614,681$.

\section{Results and Discussion}

Initially, mixed cyclization of 4-benzyloxyphthalodinitrile (1) with 4-tert-butylphthalodinitrile (2) in the presence of zinc acetate gave 2-benzyloxy-9,16,23-tritert-butylphthalocyanine. However, it was shown by TLC data this product and a side zinc phthalocyanine have close $R_{\mathrm{f}}$ values. That is why, we have treated a mixture by $\mathrm{H}_{2} \mathrm{SO}_{4}$ without preliminary isolation of intermediate product. As a result compound 3 was obtained in $50 \%$ yield. Presence of $\mathrm{OH}$-group in compound $\mathbf{3}$ has allowed us to synthesize of homo- and heteroligand complexes.

So, reaction of $\mathbf{3}$ with bis(bromomethyl)benzene (4) gave binuclear phthalocyanine $\mathbf{5}$ of clamshell-type.

Due to the high reactivity of dibromide 4 , the reagent ratio should be taken into account in this synthesis. The 

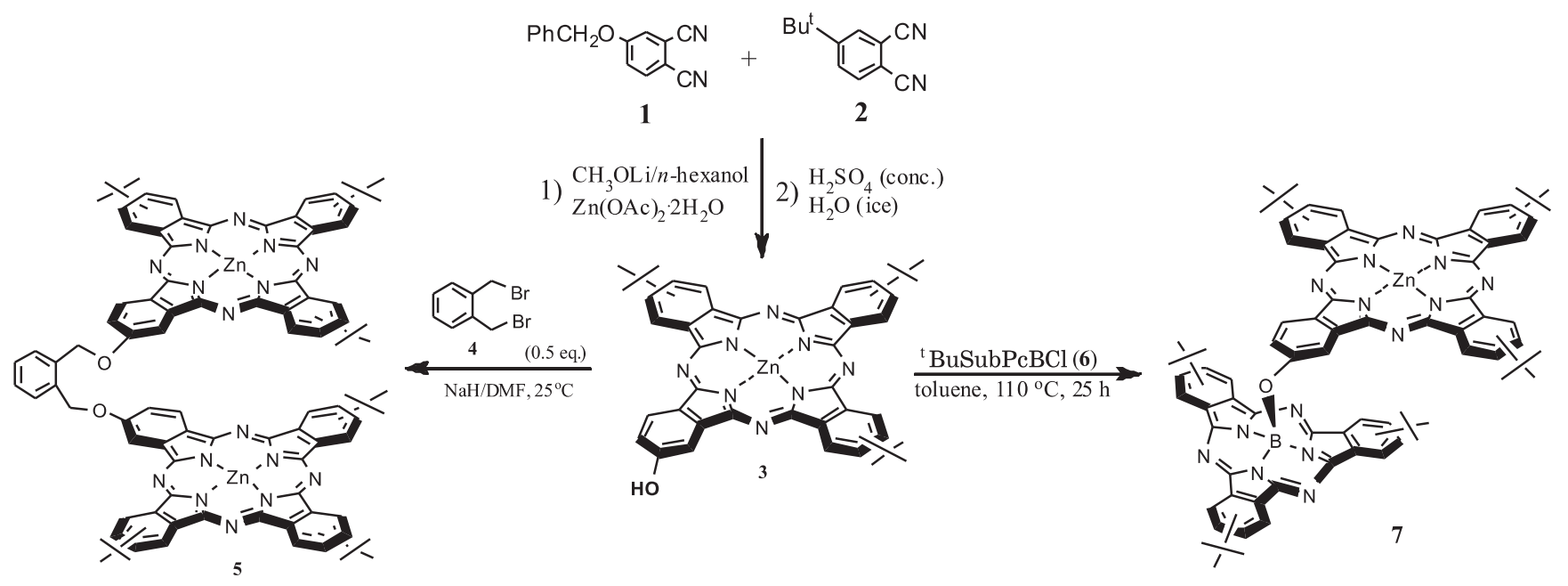

Scheme 1. Synthesis of monohydroxyphthalocyanine 3, homo- (5) and heteronuclear (7) complexes.

reaction was carried out in DMF in the presence of $\mathrm{NaH}$. Initially, the treatment of compound 3 with $\mathrm{NaH}\left(25^{\circ} \mathrm{C}\right)$ in the reaction mixture gave phenol-type alkoxy anions required for nucleophilic coupling. After addition of $\mathbf{4}$ in 0.5 equivalent quantity we managed to obtain the binuclear complex 5 with high selectivity and 95\% yield. However, it is important to note that the yield of the target binuclear phthalocyanine $\mathbf{5}$ drastically decreased upon a considerable increase of the reaction temperature due to the destruction of phthalocyanine macrocycles in the highly basic medium. This reaction gives a single product, namely, homonuclear phthalocyanine complex $\mathbf{5}$ with quantitative conversion of starting compound 3. It is important to note that the total yield of phthalocyanine $\mathbf{5}$ at two-stage synthesis was $47 \%$ that almost in 4 times more than yields of the similar compounds obtained by Leznoff. ${ }^{[6]}$

We have previously found that nonsymmetricallysubstituted monophthalocyanines containing a benzyl-type
$\mathrm{OH}$ group in the peripheral substituent are able to react with subphthalocyanines to give heteronuclear complexes. ${ }^{[7]}$ In the case of $\mathbf{3}$ we have also demonstrated the possibility of phenol-type $\mathrm{OH}$-group to give related compounds. The reaction of compound 3 with $\mu$-chloro-[boron-2,9,16-tritert-butylsubphthalocyanine] (6) resulted in a heteronuclear complex 7. It was found that the decrease in the distance between the macrocycles in compound 7 create certain steric hindrance that primarily results in a considerable increase in the reaction time in comparison with the related heterodimer that we obtained previously. ${ }^{[7]}$

Structures of compounds 3, 5, 7 were proved by MSspectrometry, ${ }^{1} \mathrm{H}$ NMR and IR-spectroscopy. So, massspectrum MALDI-TOF (2-[(2E)-3-(4-tert-butylphenyl)2-methylprop-2-enylidene]malonitrile as a matrix) of $\mathbf{3}$ contains only peak with $\mathrm{m} / \mathrm{z} 760\left([\mathrm{M}+\mathrm{H}]^{+}\right)$. The mass-spectra of complexes $\mathbf{5}$ and $\mathbf{7}$ contain, in addition to molecular ion peak $(\mathrm{m} / \mathrm{z} 1626$ and 1341), also signals of fragment ions

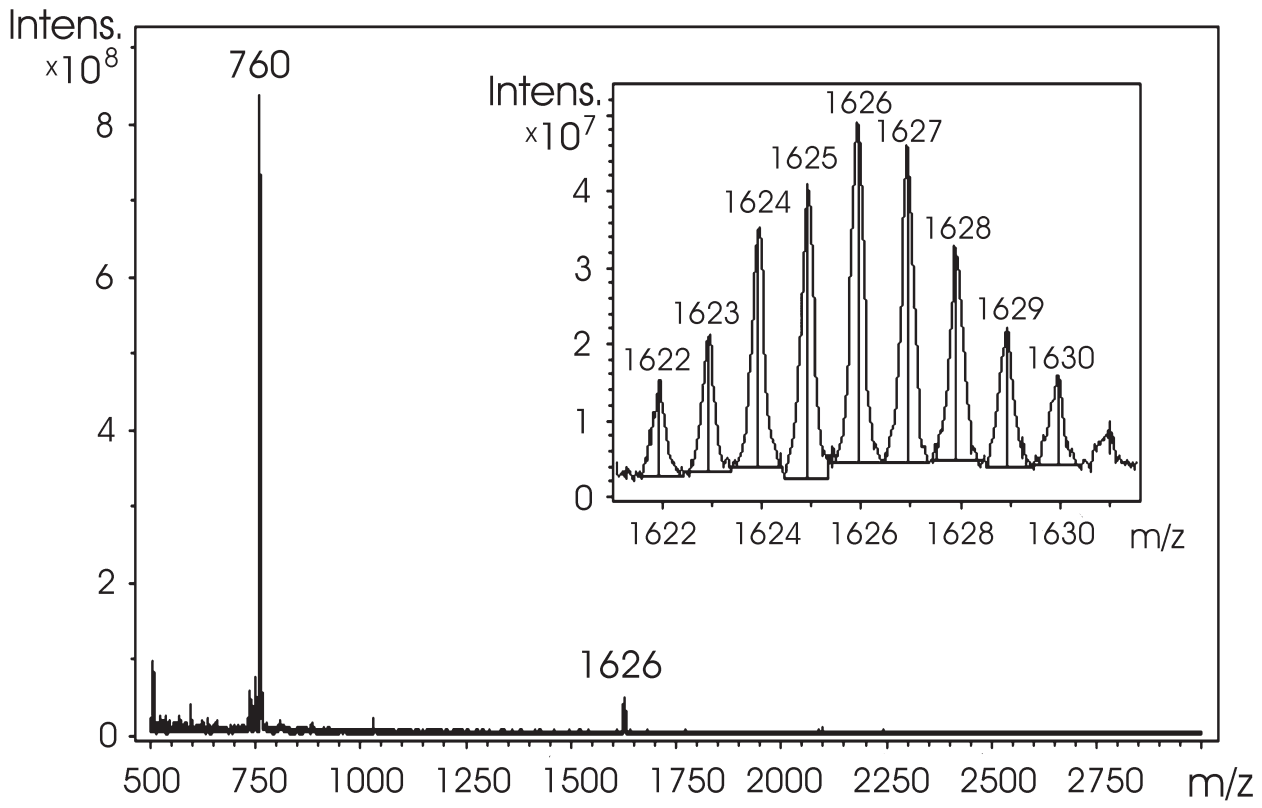

Figure 1. Mass-spectrum (MALDI-TOF) of binuclear phthalocyanine 5. 
$\left(\mathrm{m} / \mathrm{z} 760\right.$ and 581) formed upon cleavage of $\mathrm{CH}_{2}-\mathrm{OPc}$ and ether bonds correspondingly. Mass-spectrum of compound 5 is presented in Figure 1.

Peaks of all ions in mass-spectra have the charac-teristic isotope splitting peculiar to natural distribution of isotopes.

In ${ }^{1} \mathrm{H}$ NMR spectra of target phthalocyanines $\mathbf{3 , 5}$ and 7 signals of all proton types are presented. Mainly, signals of aromatic protons are found widened owing to aggregation of macrocycles and presence of statistical isomers. Signals of tert-butyl groups are detected in the form of imposed singlets (group of signals) in a range of 1.2-1.4 ppm. Singlet of benzyle-type protons of compound $\mathbf{5}(4 \mathrm{H})$ is observed at $5.5 \mathrm{ppm}$. The ${ }^{11} \mathrm{~B}$ NMR spectrum of compound 7 was found to contain a singlet at $-15.20 \mathrm{ppm}$ that is somewhat shifted upfield in comparison with compound $6 .^{[7]}$

\section{Conclusions}

Unsymmetrically substituted complex $\mathbf{3}$ was synthesized and used as a precursor for obtaining homo(5) and heteronuclear (7) complexes in the practically quantitative yields.
Acknowledgements. This work was supported by the Russian Foundation for Basic Research (Grant no. 08-0333202) and by the Programme for fundamental studies of Presidium of the Russian Academy of Sciences "Development of synthetic methods for chemical compounds and creation of novel materials".

\section{References}

1. Tolbin A.Yu., Tomilova L.G. Mendeleev Commun. 2008, 18, 286-288.

2. Tolbin A.Yu., Tomilova L.G., Zefirov N.S. Russ. Chem. Rev. 2007, 76, 681-692.

3. Sukeguchi D., Yoshiyama H., Shibata N., Nakamura S., Toru T., Hayashi Y., Soga T. J. Fluor. Chem. 2009, 130, 361-364.

4. Kikuchi D., Sakaguchi S., Ishii J. J. Org. Chem. 1998, 63, 6023-6026.

5. Claessens C.G., Gonzalez-Rodriguez D., Torres T. Chem. Rev. 2002, 102, 835-853.

6. Marcuccio S.M., Svirskaya P.I., Greenberg S., Lever A.B.P., Leznoff C.C. Can. J. Chem. 1985, 63, 3057-3069.

7. Tolbin A.Yu., Breusova M.O., Pushkarev V.E., Tomilova L.G. Russ. Chem. Bull. 2005, 54, 2083-2087.

Received 29.04.2009

Accepted 22.05.2009 